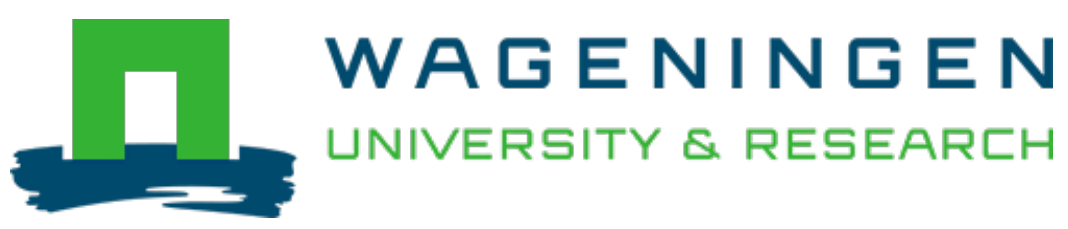

\title{
Bioinformatics of edible yellow mealworm (Tenebrio molitor) proteome reveal the cuticular proteins as promising precursors of dipeptidyl peptidase-IV inhibitors
} Journal of food biochemistry

Dávalos Terán, Irene; Imai, Kento; Lacroix, Isabelle M.E.; Fogliano, Vincenzo; Udenigwe, Chibuike C. https://doi.org/10.1111/jfbc.13121

This article is made publicly available in the institutional repository of Wageningen University and Research, under the terms of article $25 \mathrm{fa}$ of the Dutch Copyright Act, also known as the Amendment Taverne. This has been done with explicit consent by the author.

Article 25 fa states that the author of a short scientific work funded either wholly or partially by Dutch public funds is entitled to make that work publicly available for no consideration following a reasonable period of time after the work was first published, provided that clear reference is made to the source of the first publication of the work.

This publication is distributed under The Association of Universities in the Netherlands (VSNU) 'Article $25 \mathrm{fa}$ implementation' project. In this project research outputs of researchers employed by Dutch Universities that comply with the legal requirements of Article $25 \mathrm{fa}$ of the Dutch Copyright Act are distributed online and free of cost or other barriers in institutional repositories. Research outputs are distributed six months after their first online publication in the original published version and with proper attribution to the source of the original publication.

You are permitted to download and use the publication for personal purposes. All rights remain with the author(s) and / or copyright owner(s) of this work. Any use of the publication or parts of it other than authorised under article $25 \mathrm{fa}$ of the Dutch Copyright act is prohibited. Wageningen University \& Research and the author(s) of this publication shall not be held responsible or liable for any damages resulting from your (re)use of this publication.

For questions regarding the public availability of this article please contact openscience.library@,wur.nl 


\title{
Bioinformatics of edible yellow mealworm (Tenebrio molitor) proteome reveal the cuticular proteins as promising precursors of dipeptidyl peptidase-IV inhibitors
}

\author{
Irene Dávalos Terán ${ }^{1}$ | Kento Imai ${ }^{2,3}$ | Isabelle M. E. Lacroix ${ }^{4}$ (D) | Vincenzo Fogliano ${ }^{1}$ (D) | \\ Chibuike C. Udenigwe ${ }^{1,2,5}$ (C)
}

\author{
${ }^{1}$ Food Quality \& Design Group, Wageningen \\ University and Research, Wageningen, The \\ Netherlands \\ ${ }^{2}$ School of Nutrition Sciences, Faculty of \\ Health Sciences, University of Ottawa, \\ Ottawa, Ontario, Canada \\ ${ }^{3}$ Department of Biomolecular Engineering, \\ Graduate School of Engineering, Nagoya \\ University, Nagoya, Japan \\ ${ }^{4}$ Food Bio-based Research, Wageningen \\ University and Research, Wageningen, The \\ Netherlands \\ ${ }^{5}$ Department of Chemistry and Biomolecular \\ Sciences, Faculty of Science, University of \\ Ottawa, Ottawa, Ontario, Canada

\section{Correspondence} \\ Chibuike C. Udenigwe, School of Nutrition \\ Sciences, Faculty of Health Sciences, \\ University of Ottawa, Ottawa, Ontario K1H \\ 8L1, Canada. \\ Email: cudenigw@uottawa.ca
}

\begin{abstract}
Bioinformatics was applied for strategic processing of yellow mealworm (Tenebrio molitor) proteins to produce dipeptidyl peptidase (DPP)-IV inhibiting peptides. In silico analysis of 384 mealworm proteins revealed structural proteins as better precursors of DPP-IV inhibiting peptides, compared with other protein types, after pepsin and papain hydrolysis. This was associated with the higher hydropathicity and amounts of residues associated with DPP-IV inhibition in the structural (cuticular) proteins. In silico, the peptides were mostly released with pepsin than papain. Cuticular (CP) and non-cuticular proteins (NC) were extracted from yellow mealworm and hydrolyzed with pepsin and papain in vitro to validate the virtual findings. CP hydrolysate with papain inhibited DPP-IV the most compared to CP hydrolysate with pepsin, whereas NC hydrolysates were mostly inactive. $\mathrm{CP}$ had higher hydrophobic-hydrophilic amino acid ratios and contents of the activity-associated residues than NC. The findings demonstrate the application of bioinformatics in processing proteins for bioactive peptide production.
\end{abstract}

\section{Practical applications}

The discovery of bioactive peptides from food proteins is typically based on the classic approach involving working with a small number of protein-protease combinations in vitro. For the first time, this study reported the application of in silico tools in comprehensively studying hundreds of proteins from yellow mealworm (an edible insect) as sources of DPP-IV inhibitors, followed by in vitro processing and validation guided by the results obtained in silico. The advantage of this approach is that it allows for analysis of several protein-protease combinations (with multiple datasets of structural, functional, and bioactivity parameters) in a short time. This work is relevant in advancing research on emerging or alternative proteins as well as structureinformed food protein processing. The bioinformatics approach can be adapted for strategic processing of proteins in the food industry prior to making major resource investments. 


\section{KEYWORDS}

bioactive peptides, bioinformatics, cuticular proteins, dipeptidyl peptidase-IV, edible insects, hydrophobicity, Tenebrio molitor

\section{1 | INTRODUCTION}

Several food proteins are precursors of bioactive peptides with dipeptidyl peptidase (DPP)-IV inhibitory activities (Lacroix \& Li-Chan, 2016). Inhibiting DPP-IV activity leads to an increase of insulin secretion and therefore a decrease in blood glucose level in vivo (Mochida, Hira, \& Hara, 2010; Ishikawa et al., 2015). This activity is relevant in managing type 2 diabetes (T2D), which is a public health concern. DPP-IV (also known as DPP-4 or cluster of differentiation 26 ) is a soluble or membrane-anchored enzyme that degrades incretin hormones, glucagon-like peptide (GLP)-1 and glucose-dependent insulinotropic polypeptide, inactivating more than $95 \%$ of the GLP-1 produced in the body (Lacroix \& Li-Chan, 2016). Incretin hormones are responsible for $50 \%-70 \%$ of total insulin secretion in response to nutrient intake (Edholm et al., 2010). Therefore, their activity is important in maintaining normal glucose levels in the blood. A 2015 report showed that one in 11 adults has T2D and this number was predicted to increase over time (Cho, 2015). DPP-IV inhibiting compounds used as effective treatment options for T2D are known as gliptins (Nongonierma \& FitzGerald, 2013).

The most widely used method to release bioactive peptides from their parent proteins is enzymatic hydrolysis, which yields dipeptides, tripeptides, and small oligopeptides (Udenigwe \& Aluko, 2012). Several proteases have been used to generate DPP-IV inhibiting peptides, including digestive enzymes (de Souza Rocha, Hernandez, Chang, \& de Mejía, 2014) and industrial enzymes produced by microorganisms and those obtained from plants (Lacroix \& Li-Chan, 2016). Highly active DPP-IV inhibiting peptides typically contain a Trp residue at $P_{1}\left(\mathrm{~N}\right.$-ter) position or Pro residues at $P_{2}$ position (Nongonierma $\&$ FitzGerald, 2014). Food-derived peptides have low biostability due to their scissile peptide bonds (Udenigwe \& Fogliano, 2017), and their bioavailability is reported to be in amounts as low as pico- and nanomolar concentrations (Xu, Hong, Wu, \& Yan, 2019). Moreover, inhibitory effect of food peptides is lower than that of rationally designed synthetic gliptins (Lacroix \& Li-Chan, 2016). Nonetheless, food protein-derived peptides are promising as functional ingredients for managing T2D and as natural adjuvant to support the effect and reduce the use of synthetic DPP-IV inhibiting drugs.

Bioinformatics has the capability to cost-effectively speed up the process of predicting and producing bioactive peptides from food proteins, although the procedure is still faced with challenges, for example, inability to simulate enzymatic hydrolysis of 3-dimensional protein structures in silico (Udenigwe, 2014; Agyei, Tsopmo, \& Udenigwe, 2018). Most studies on bioactive peptides are based on traditional protein sources (e.g., milk and soybean). Emerging protein sources, for example, edible insects, are increasingly gaining traction as sustainable resources for promoting food security. Some insect species have high nutritional value and protein content. Yellow mealworm (Tenebrio molitor) is one of the major edible insects currently reared on an industrial scale ( $\mathrm{Yi}$, Van Boekel, Boeren, \& Lakemond, 2016). Fresh larvae typically contain $24.3 \%-27.6 \%$ protein, which compares favorably with meat protein products containing 15\%-22\% protein (Yi, Van Boekel, \& Lakemond, 2017). Previous studies have used the classic approach to generate bioactive hydrolysates, including DPP-IV inhibitors, from edible insect proteins for potential nutraceutical applications (Lacroix, Dávalos Terán, Fogliano, \& Wichers, 2019; Nongonierma, Lamoureux, \& FitzGerald, 2018). Considering the limited sample coverage and costly and time-consuming features of the classic approach, the objective of this study was to use the bioinformatics approach to strategically guide the selection and fractionation of edible insect (yellow mealworm) proteins for the production of potent DPP-IV inhibiting peptides.

\section{2 | MATERIALS AND METHODS}

\subsection{In silico analysis of mealworm proteins and peptides}

A total of 384 sequences of yellow mealworm proteins and one sequence of bovine $\beta$-lactoglobulin ( $\beta$ - Lg; used as control) were obtained from UniProt Knowledgebase at http://www.uniprot.org/. The search was conducted between November 2016 and February 2017 using the query "yellow mealworm" and both Swiss-Prot and TrEMBL database entries were considered. Multiple protein entries were excluded from the dataset prior to analysis. The following protein information was obtained from UniProtKB: amino acid sequence using FASTA; grand average of hydropathicity (GRAVY) and theoretical isoelectric point ( $\mathrm{pl}$ ) using ProtParam; and biological role listed under "Function". In silico enzymatic hydrolysis of the 385 proteins was performed using BIOPEP-UWM "enzyme action" tool at http:// www.uwm.edu.pl/biochemia/index.php/en/biopep (Minkiewicz, Dziuba, Iwaniak, Dziuba, \& Darewicz, 2008). Signal peptides were deleted and mature proteins were virtually digested with two proteases: pepsin ( $\mathrm{pH}>2$; EC 3.4.23.1) and papain (EC 3.4.22.2) (Udenigwe, 2016). Thereafter, parameters " $A_{E}$ " (frequency of release of fragments with given activity by selected enzymes) and "W" (relative frequency of release of fragments with given activity by selected enzymes) were calculated for each protein sequence and the $\beta$-Lg control. Parameter "A" (frequency of bioactive fragments occurrence in the protein sequence) was also calculated ( $A=A_{E} / W$ ) (Minkiewicz et al., 2008). 
Proteins were classified according to three categories prior to analysis: theoretical pl, biological role, and GRAVY. $\beta$-Lg was included in all the categories. For pl, proteins were further classified as acidic (pl 1.00-6.49), neutral (pl 6.50-7.49), and basic (pl 7.50-14.00). For biological role, proteins were classified as signaling, structural, enzymatic, and other functions. For GRAVY, proteins were classified as hydrophilic (GRAVY -2. to 0) and hydrophobic (GRAVY 0.01-2). For each category, graphs of $A_{E}$ versus $A$ were plotted for in silico digests of the proteins with pepsin and papain. Amino acid frequencies were also calculated for the proteins using $\mathrm{R}$ program and graphed using Seq2Logo 2.0 available at http://www.cbs.dtu.dk/biotools/Seq2L ogo/. Results from the in silico analysis determined the mealworm protein types and processing targeted for in vitro experiments.

\section{2 | Mealworm preparation}

Fresh yellow mealworm (T. molitor) larvae (aged 10-12 weeks) were purchased from Kreca Ento-Feed BV (Ermelo, The Netherlands). The larvae were washed and frozen by immersion in liquid nitrogen ( $\mathrm{Yi}$ et al., 2017) and then blended with sulfite $(1.6 \%, w / v)$ to prevent enzymatic browning. The mixture was blended for $1 \mathrm{~min}$, frozen at $-20^{\circ} \mathrm{C}$, and freeze-dried until the weight was stable. Thereafter, the dried samples were milled using Retsch MM 400 mill at a frequency of $30 / \mathrm{s}$ for $6 \mathrm{~s}$, to obtain a powder. The mealworm powder was then defatted with hexane at a solid-to-solvent ratio of 1:5 (w/v).

\section{3 | Mealworm protein fractionation}

Based on the in silico results, mealworm cuticular proteins (CP) were targeted in this study. CP extraction was based on the method described by Andersen, Rafn, Krogh, Hojrup, and Roepstorff (1995). Non-cuticular proteins (NC) were extracted from defatted mealworm meal $(10 \%, \mathrm{w} / \mathrm{v})$ in $1 \%$ potassium tetraborate decahydrate, $\mathrm{pH}$ 9.1. The mixture was homogenized with Ultra-Turrax ${ }^{\circledR}$ (IKA T25 digital) at 3,000 rpm. The mixture was centrifuged at 4,000 $\mathrm{g}$ for $10 \mathrm{~min}$. The supernatant was separated from the residue and frozen at $-20^{\circ} \mathrm{C}$. The residue was washed once with $1 \%$ potassium tetraborate decahydrate followed by a final wash with Milli-Q water. Proteins present in the residue (CP) were extracted with $6 \mathrm{M}$ urea in $0.02 \mathrm{M}$ ammonium acetate (96\%, Merck) at 1:4 (w/v), $\mathrm{pH} 5.0 ; \mathrm{pH}$ was adjusted with $0.1 \mathrm{M}$ acetic acid. The mixture was left at $4{ }^{\circ} \mathrm{C}$ for $15 \mathrm{hr}$, centrifuged at $4,000 \mathrm{~g}$ for $10 \mathrm{~min}$, and the supernatant was collected and frozen at $-20^{\circ} \mathrm{C}$. The protein fractions were concentrated in a freeze dryer to reduce the volume by $~ 50 \%$ and dialyzed using a membrane of 2,000 Da molecular weight cutoff to remove salt and other non-protein components. The retentate was frozen at $-20^{\circ} \mathrm{C}$ and freeze-dried until the weight was stable. Freeze-dried mealworm proteins were milled to obtain the NC and CP powders. $\mathrm{NC}$ and $\mathrm{CP}$ protein content was determined by the bicinchoninic acid (BCA) method using the Pierce ${ }^{\mathrm{TM}}$ BCA Protein Assay Kit (Thermo Scientific). Crude protein content was also determined by Dumas
(FLASHEA 1112 series, Interscience, Thermo Scientific) using D-methionine (99\%, Acros Organics) as a standard and a conversion factor of 6.25 was used (Yi et al., 2016).

\subsection{Amino acid composition of the proteins}

Amino acid composition (\%) of NC and CP was analyzed at the SPARC BioCentre, The Hospital for Sick Children (Toronto, Canada), using the Pico-Tag method after vapor-phase hydrolysis with $6 \mathrm{M}$ $\mathrm{HCl} / 1 \%$ phenol at $110^{\circ} \mathrm{C}$ for $24 \mathrm{hr}$, pre-column derivatization with phenyl isothiocyanate, and reverse-phase ultra-performance liquid chromatography using a Waters ACQUITY UPLC (Milford, MA, USA), as previously reported (Mohan \& Udenigwe, 2015).

\section{5 | Sodium dodecyl sulfate-polyacrylamide gel electrophoresis}

Protein profiles of NC and CP were analyzed using NuPAGE ${ }^{\circledR}$ gels (12\% Bis/Tris with 10 wells), NuPAGE ${ }^{\circledR}$ MES running buffer, and a blue ray prestained 10-180 kDa protein marker (Jena Bioscience). Details of the experiment are provided in the supporting information.

\section{6 | Protein surface hydrophobicity}

Surface hydrophobicity of NC and CP was determined using the fluorescent probe, 8-anilino-1-naphthalenesulphonic acid (ANS), as described by Mohan and Udenigwe (2015). Surface hydrophobicity was obtained as the slope of the fluorescence intensity versus concentration plot.

\section{7 | Enzymatic hydrolysis of mealworm protein fractions}

NC and CP from yellow mealworm and bovine $\beta$ - $\operatorname{Lg}(\geq 90 \%$, SigmaAldrich; used as protein control) were hydrolyzed with two proteases: pepsin (2,500 FIP-U/g, Merck) and papain (from papaya latex, 1.5-10 units/mg, Sigma-Aldrich). Temperature and $\mathrm{pH}$ conditions for hydrolysis were set at the optimal conditions for protease activity, that is, $\mathrm{pH} 2.0\left(0.1 \mathrm{M} \mathrm{KCl}-\mathrm{HCl}\right.$ buffer) at $37^{\circ} \mathrm{C}$ for pepsin (Lacroix \& Li-Chan, 2014) and pH 6.5 (0.1 M sodium phosphate buffer) at $55^{\circ} \mathrm{C}$ for papain (Bah, Bekhit, Carne, \& McConnell, 2015). The sample solutions had a concentration of $5 \%(\mathrm{w} / \mathrm{v}$, protein basis) and the enzyme/ substrate (E/S) ratio was 1:100 (w/w) (Lafarga, Aluko, Rai, O'Connor, $\&$ Hayes, 2016). All samples were hydrolyzed for $5 \mathrm{hr}$ under constant shaking ( $50 \mathrm{rpm}$ ) in triplicate. Thereafter, $\mathrm{pH}$ was adjusted to 7.0 with $0.5 \mathrm{M} \mathrm{NaOH}$ and to stop the hydrolysis, samples were placed on ice and centrifuged at 4,700 g for $5 \mathrm{~min}$. The supernatants were frozen at $-20^{\circ} \mathrm{C}$ followed by freeze-drying and milling to obtain the hydrolysate powders. Extent of protein hydrolysis was determined as free 
amino nitrogen (FAN, milliequivalent serine- $\mathrm{NH}_{2} / \mathrm{g}$ protein) in the samples (Nielsen, Petersen, \& Dambmann, 2001), using o-phthalaldehyde (OPA) reagent and a standard, L-serine (ReagentPlus ${ }^{\circledR}$, $\geq 99 \%$, Sigma-Aldrich) at $0.9516 \mathrm{meqv} / \mathrm{L}$.

\subsection{Determination of DPP-IV inhibitory activity}

DPP-IV inhibition assay was carried as described by Lacroix and LiChan (2013). Proteins and hydrolysates were dissolved in Tris- $\mathrm{HCl}$ buffer ( $\mathrm{pH} 8.0$ ), and the final assay concentration was $0.375 \mathrm{mg} / \mathrm{ml}$ (protein basis, Dumas). In a 96-well plate, $25 \mu \mathrm{l}$ of sample and $25 \mu \mathrm{l}$ of 12 mM DPP-IV substrate, Gly-Pro-p-nitroanilide (Bachem), were incubated for $10 \mathrm{~min}$ at $37^{\circ} \mathrm{C}$. Thereafter, $50 \mu \mathrm{l}$ of DPP-IV $(1,852$ unit/ml, human recombinant, Sigma-Aldrich) was added and incubated at $37^{\circ} \mathrm{C}$ for $30 \mathrm{~min}$. The reaction was stopped with $100 \mu \mathrm{l}$ of $1 \mathrm{M}$ sodium acetate buffer ( $\mathrm{pH} 4.0)$. Absorbance was measured at $405 \mathrm{~nm}$ using the Infinite M200 Pro microplate reader (Tecan, The Netherlands). Samples were analyzed in triplicate and absorbance was corrected using a blank in which DPP-IV was replaced with the buffer. Activity of the samples was expressed as \% DPP-IV inhibition. Half-maximal inhibitory concentration $\left(\mathrm{IC}_{50}\right)$ of $\mathrm{CP}$ hydrolysate obtained with papain and diprotin A (lle-Pro-lle, $\geq 97 \%$ (HPLC), Sigma-Aldrich) was determined as previously reported (Lacroix \& LiChan, 2014).

\subsection{Data and statistical analysis}

Results were expressed as mean of triplicate determinations \pm standard deviation. One-way analysis of variance was performed followed by post hoc Tukey's honest significant differences test using $\mathrm{R}$ program with a significance level at $p<.05$. Relationship between $A_{E}$ and $A$ was determined by Pearson's correlation. The in silico parameters of the structural proteins (for each protease hydrolysis) was compared with parameters from each of the other protein types by Student $t$ test.

\section{3 | RESULTS AND DISCUSSION}

\section{1 | In silico parameters of yellow mealworm proteins as precursors of DPP-IV inhibitors}

Yellow mealworm proteins were grouped into three categories to understand the types, location, and properties of the most promising precursors of DPP-IV inhibiting peptides. This information guided wet laboratory processing of the edible insect larvae. $\beta$ - Lg, used as protein control, is a precursor of DPP-IV inhibiting peptides derived from whey proteins. Pepsin (aspartate protease) and papain (cysteine protease) were used as model proteases because they have different catalytic mechanisms, recognition and cleavage sites, and have been applied in generating DPP-IV inhibiting protein hydrolysates.
Compared with frequency of occurrence of bioactive peptides (A), the release of the peptides by a given protease $\left(A_{E}\right)$ is a more useful parameter for assessing if the peptides can be practically generated during protein hydrolysis. After classifying the mealworm proteins based on theoretical pl, scatter plots of $A_{E}$ versus $A$ did not result in a clear pattern or relationship for in silico hydrolysates derived from pepsin and papain (Figures S1 and S2, supporting information). Thus, separation of the insect proteins based on $\mathrm{pl}$, as done during protein isolation, would not lead to fractionation of the best precursors of DPP-IV inhibiting peptides.

The biological role of proteins determines their cellular/tissue compartmentalization, molecular structure, and chemical composition. Consequently, this factor will influence the type and physicochemical property of peptides derived from the proteins. After classifying the mealworm proteins as signaling, structural, enzymatic, and others, the structural proteins showed higher $(p<.01)$ occurrence and release frequencies of DPP-IV inhibiting peptides compared with enzymatic proteins and others, for both proteases (Figure 1a,b). Difference in $A_{E}$ was not significant $(p>.05)$ when structural proteins were compared with signaling proteins due to the small number $(n=6)$ of the latter dataset. High $A$ and $A_{E}$ parameters of the structural proteins are attributable to the nature of this type of proteins. Most of the high-scoring structural proteins in Figure $1 a, b$ are cuticular proteins. Due to their location in the insect exoskeleton, cuticular proteins contain predominantly hydrophobic amino acids within their sequences (Andersen, Hojrup, \& Roepstorff, 1995). Many hydrophobic amino acids are found in potent DPP-IV inhibiting peptides (Hsu, Tung, Huang, \& Jao, 2013), as they facilitate peptide binding to hydrophobic pockets of the enzyme active site. When frequency of release of peptides from the 384 mealworm proteins was compared, pepsin gave higher $A_{E}$ than papain for 277 proteins (75.6\%), same $A_{E}$ for 21 proteins $(5.7 \%)$, and papain gave higher $A_{E}$ for 68 proteins (18.5\%) (excluding 18 proteins with $A_{E} 0$ ). Thus, pepsin releases more DPP-IV inhibiting peptides from the mealworm proteins in silico than papain.

To investigate the physicochemical property behind the relationships, the mealworm proteins were classified as hydrophilic and hydrophobic as shown in Figure 2a,b for proteins digested by pepsin and papain, respectively. $A$ and $A_{E}$ were higher for mealworm proteins with the highest hydropathicity values. From Figures 1 and 2, structural proteins have the highest hydrophobic character of the mealworm proteins. Therefore, structural functionality is predicted as the most suitable for fractionating the insect protein precursors of DPP-IV inhibiting peptides. Hsu et al. (2013) reported that hydrophobic amino acids Pro, Leu, Val, Phe, Ala and Gly are important peptide features for DPP-IV inhibition, with Pro being the most important. When examined in detail, total content of the activity-associated amino acids (Figure 3a) was about 35\% (signaling, 33\%; enzymatic, 39\%; others, 36\%; and $\beta$ - Lg, 38\%), except for structural proteins, which had $60 \%$. Thus, the mealworm structural proteins have higher amounts of valuable amino acids for DPP-IV inhibition compared with the other protein types. The structural proteins are mainly composed of cuticular proteins, which have hydrophobic 
(a)

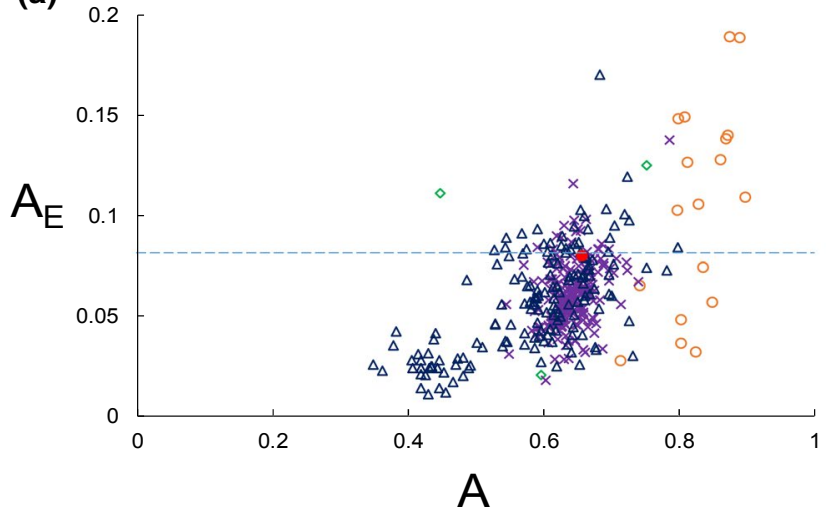

(b)

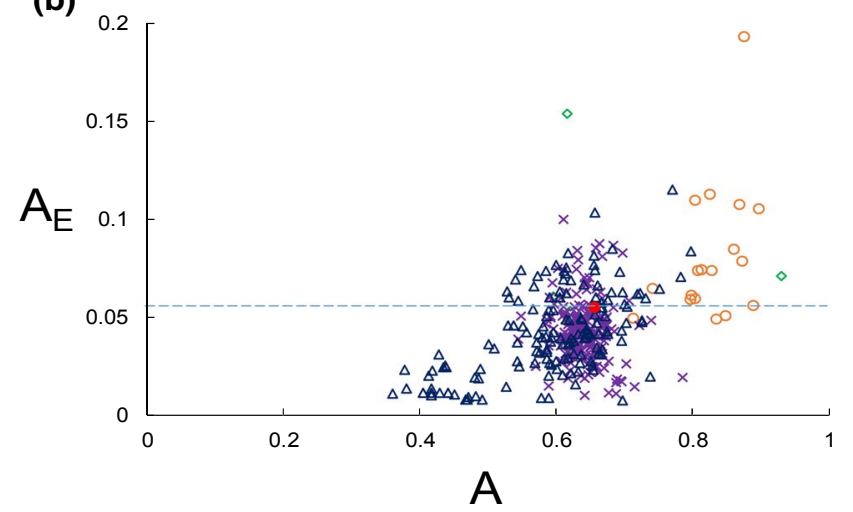

FIGURE 1 Scatter plots of parameters obtained from virtual digestion of Tenebrio molitor protein sequences and bovine $\beta$-lactoglobulin with (a) pepsin and (b) papain; $A_{E}$, frequency of release of bioactive peptides with DPP-IV inhibitory activity; A, frequency of occurrence of bioactive peptides with DPPIV inhibitory activity. Each symbol represents a single protein sequence. Proteins were classified according to their biological function in Tenebrio molitor and divided into four subgroups: $\diamond$ signaling, o structural, $\times$ enzymatic, and $\Delta$ other functions. $\beta$-Lactoglobulin, included as protein control, is represented by ( $A_{E}$ highlighted by the dashed line)

character because of their protective role in the insect exoskeleton (Andersen, Hojrup, et al., 1995). Taken together, the yellow mealworm cuticular proteins have strong potential as precursors of DPP-IV inhibiting peptides.

\subsection{Protein content, amino acid composition, and profile of mealworm proteins}

To validate the in silico findings, in vitro experiments were conducted with proteins extracted from defatted yellow mealworm flour. Protein content (dry weight basis) of NC and CP, determined by BCA method, was $59.8 \%$ and $76.9 \%$, respectively. The former is lower than other mealworm protein contents in the literature. Zhao, Vázquez-Gutiérrez, Johansson, Landberg, and Langton (2016) and Azagoh et al. (2016) reported protein contents of $79 \%$ and $84 \%$, respectively, for yellow mealworm proteins extracted at alkaline $\mathrm{pH}$ at 40 and $45^{\circ} \mathrm{C}$. Using the Dumas method, NC and CP had protein (a)

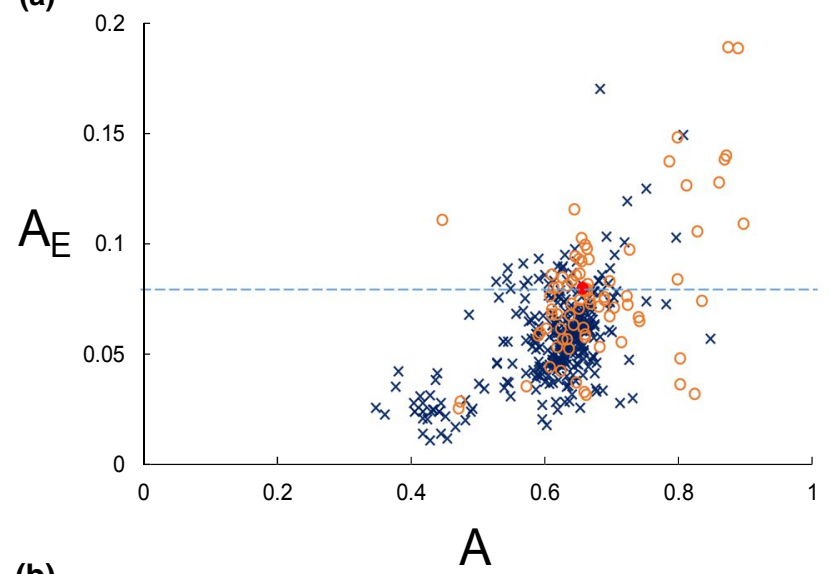

(b)

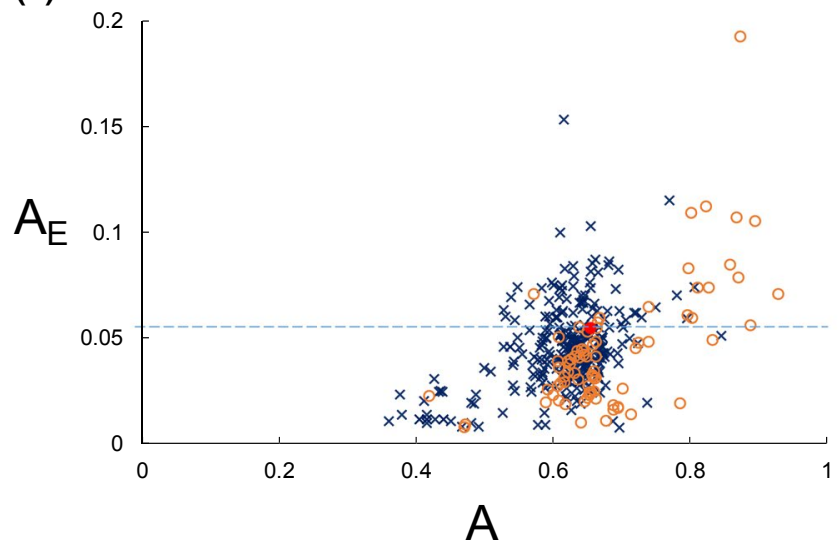

FIGURE 2 Scatter plots of parameters obtained from virtual digestion of Tenebrio molitor protein sequences and bovine $\beta$-lactoglobulin with (a) pepsin and (b) papain; $A_{E}$, frequency of release of bioactive peptides with DPP-IV inhibitory activity; A, frequency of occurrence of bioactive peptides with DPPIV inhibitory activity. Each symbol represents a single protein sequence. Proteins were classified according to their grand average of hydropathicity (GRAVY) values and divided into two subgroups: o hydrophobic (GRAVY, 0.01-2) and $\times$ hydrophilic (GRAVY, -2 to 0 ). $\beta$-Lactoglobulin was used as the protein control and is represented by $\bullet$ ( $A_{E}$ highlighted by the dashed line)

contents of $68.7 \pm 2.53 \%$ and $90.2 \pm 1.25 \%$, respectively; possibly increased by non-protein nitrogen in the samples. The differences can be due to the extraction conditions, methods of protein determination, and mealworm matrix effect.

Almost all cuticular proteins belong to structural proteins. Noncuticular proteins however are a mixture of signaling, enzymatic and proteins with other functions. In vitro, total amino acid compositions of the important contributors (Pro, Leu, Val, Phe, Ala, and Gly) to DPP-IV inhibitory activity of peptides are $32.3 \%$ and $43.2 \%$ for NC and $\mathrm{CP}$, respectively (Figure $3 \mathrm{~b}$ ), which follows the same trend as the in silico results (Figure 3a). CP had higher amounts of Gly, Ala, Val, and Pro, similar amount of Leu, and lower amount of Phe when compared to NC. The slight difference between the actual in silico and in vitro amino acid values is expected as the extraction procedure does not guarantee complete protein recovery and each protein has different natural abundance in the samples. 
(a)

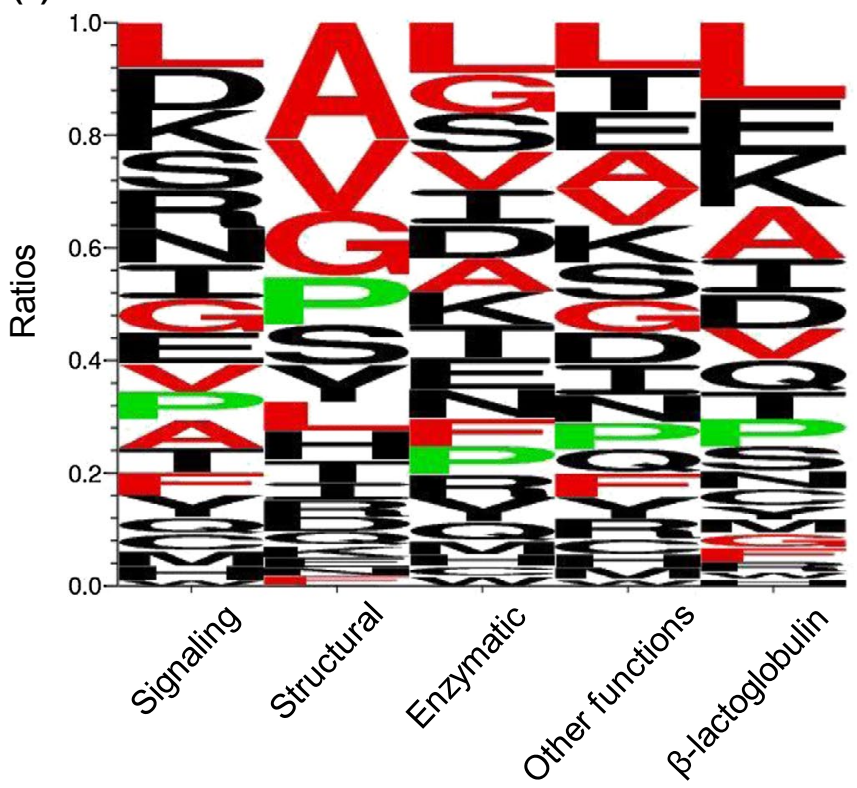

(b)

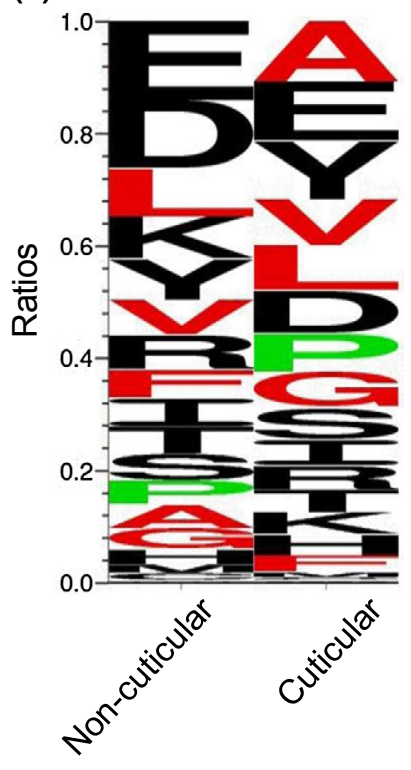

FIGURE 3 Frequency analysis of amino acid residues. (a) Calculated amino acid ratios appearing in yellow mealworm proteins separated by biological functions in silico. (b) Amino acid composition ratios of cuticular (CP) and non-cuticular proteins (NC) in vitro; $E=E+Q$ and $\mathrm{D}=\mathrm{D}+\mathrm{N}$. Red color represents the amino acids that are important for DPP-IV inhibitory activity of peptides. Green color represents Pro, which is the most important amino acid residue of peptides for DPP-IV inhibition. Other amino acids are shown with black

The protein band patterns of NC and CP are presented in Figure S3 (supporting information). CP bands, mostly appearing below $35 \mathrm{kDa}$, did not separate clearly on the gel and suggest the presence of cuticular proteins with molecular weights of $14-30 \mathrm{kDa}$ (Andersen, Hojrup, et al., 1995). For NC, major groups of protein bands were noted at 8-15 kDa, 15-31 kDa, and 31-72 kDa, as previously reported by Yi et al. (2013) and Azagoh et al. (2016) for protein extracted from whole yellow mealworm. Bands at 8.5-13 kDa are due to anti-freeze, including hemolymph, proteins (12 kDa), those at 14-32 kDa suggest the presence of soluble cuticular proteins in NC, and bands at 32-95 kDa are related to enzymatic and muscle proteins (Yi et al., 2013). Protein bands at $25-72 \mathrm{kDa}$ had the highest intensity, suggesting the predominance of enzymatic and muscle proteins in NC.

\section{3 | Surface and molecular hydrophobicity of mealworm proteins}

Hydrophobicity plays an important role in determining the properties of proteins and peptides, including bioavailability, bitterness score, solubility, self-assembly, and some bioactivities (Acquah, Di Stefano, \& Udenigwe, 2018). In this study, surface and molecular hydrophobicity were used to confirm the hydrophobic nature and evaluate the potential of the mealworm proteins as precursors of DPP-IV inhibitors. The surface hydrophobicity of CP $(176.4 \pm 21.5)$ was not different $(p>.05)$ from that of NC $(187.4 \pm 8.6)$. Azagoh et al. (2016) reported a comparable value for proteins from whole yellow mealworm meal. Surface hydrophobicity, determined using ANS, depends on the number and size of hydrophobic patches on the protein surface (Cardamone \& Puri, 1992). Although CP was expected to have higher surface hydrophobicity than NC, the similar values observed may be because hydrophobic residues in the cuticular proteins would be buried inside the protein structure in the polar environment. Moelbert (2004) reported a correlation between amino acid hydrophobicity and surface exposure. Cardamone and Puri (1992) also reported that the average hydrophobicity of amino acid sequences (Bigelow) and surface hydrophobicity (ANS) are related, with some exceptions. In our study, the molecular hydrophobicity (total compositions of hydrophobic amino acids and hydrophobic-hydrophilic amino acid ratios) was higher for CP (53.6\%; 1.15 , respectively) compared with NC (44.0\%; 0.78, respectively). This validates the in silico GRAVY data on the hydrophobic nature of exoskeletal cuticular proteins.

\subsection{Digestibility of mealworm proteins}

Extent of hydrolysis was determined to confirm that hydrolysis of $\mathrm{NC}, \mathrm{CP}$, and $\beta$ - Lg (control) had occurred with the addition of pepsin or papain. FAN values of NC hydrolysates were significantly higher $(p<.05)$ than those of CP and $\beta$ - Lg hydrolysates (Figure 4). The difference can be attributed to the predominantly hydrophobic amino acids of $\mathrm{CP}$, which are prone to interacting at elevated temperature to facilitate protein aggregation (Andersen, 2002). Consequently, the proteases would have limited access to peptide bonds in CP compared with NC, which are more soluble in water and hence available for hydrolysis. The FAN observed for the $\beta$ - Lg control is low because the protein presents a folded structure that makes it resistant to pepsin hydrolysis. It is not certain if this also explains the result obtained with papain-hydrolyzed $\beta$-Lg. 


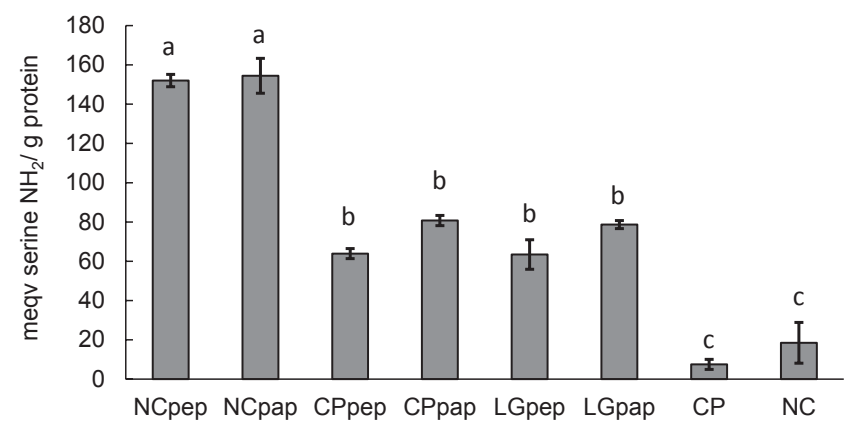

FIGURE 4 Extent of hydrolysis of the hydrolysates derived from yellow mealworm cuticular (CP) and non-cuticular proteins (NC), and $\beta$-lactoglobulin after hydrolysis with pepsin or papain. Bars with different letters are significantly different $(p<.05)$ mean values. NCpep: non-cuticular protein hydrolyzed with pepsin, NCpap: noncuticular protein hydrolyzed with papain, CPpep: cuticular protein hydrolyzed with pepsin, CPpap: cuticular protein hydrolyzed with papain, LGpep: $\beta$-lactoglobulin hydrolyzed with pepsin, and LGpap: $\beta$-lactoglobulin hydrolyzed with papain

\subsection{DPP-IV inhibitory activities of the mealworm protein hydrolysates}

DPP-IV inhibitory activity of the NC, CP, and $\beta$ - Lg (control) hydrolysates are shown in Figure 5. Both CP hydrolysates had the highest DPP-IV inhibitory activity, with CP hydrolysate with papain exhibiting the best effect ( $30.4 \%$ inhibition at $0.375 \mathrm{mg} / \mathrm{ml} ; p<.05)$. The findings support the in silico results (Figure 2a,b) and suggest a possible connection to hydrophobicity of cuticular proteins. Potent DPP-IV inhibiting dipeptides are hydrophobic and contain Pro flanked by Ala, Gly, Leu, Val or Phe (Hsu et al., 2013). Papain has a broad cleavage specificity with preference for peptide bonds with hydrophobic residues located at $P_{2}$ only (Barrett, Rawlings, \& Woessner, 1998). Thus, the hydrophobic amino acids, Ala, Val, Leu, lle, Phe, Trp, and Tyr, are exposed in the resulting peptides at $P_{2}$ (penultimate $\mathrm{C}$-ter), making the peptides potential substrate-type DPP-IV inhibitors. On the other hand, pepsin (less specific at $\mathrm{pH}>2$ ) has a preference for cleaving proteins at several hydrophobic amino acid residues (Phe, Ala, Val, Leu, Ile, Phe, Trp, and Tyr) at both $P_{1}$ or $P_{1}^{\prime}$ (ExPASy Peptide Cutter, https://web.expasy.org/ peptide_cutter/). This explains the better action of pepsin in releasing DPP-IV inhibiting peptides in silico compared to papain.

In silico prediction of the preferred protease was however not validated in vitro using the extracted mealworm proteins. Similar result was recently reported for pigeon pea protein precursors of DPP-IV inhibitors (Boachie et al., 2019). This discrepancy can be because the virtual digestion uses the linear protein structure due to lack of bioinformatics tools that simulate enzyme-protein interactions occurring during in vitro digestion of 3-dimensional proteins. Moreover, the mealworm proteins are not completely solubilized at the acidic $\mathrm{pH}$ condition of pepsin in vitro, which will hinder accessibility of the protease to cleavage sites on the proteins (Boachie et al., 2019). Nonetheless, the bioinformatics approach systematically guided the selection of cuticular proteins as the most promising

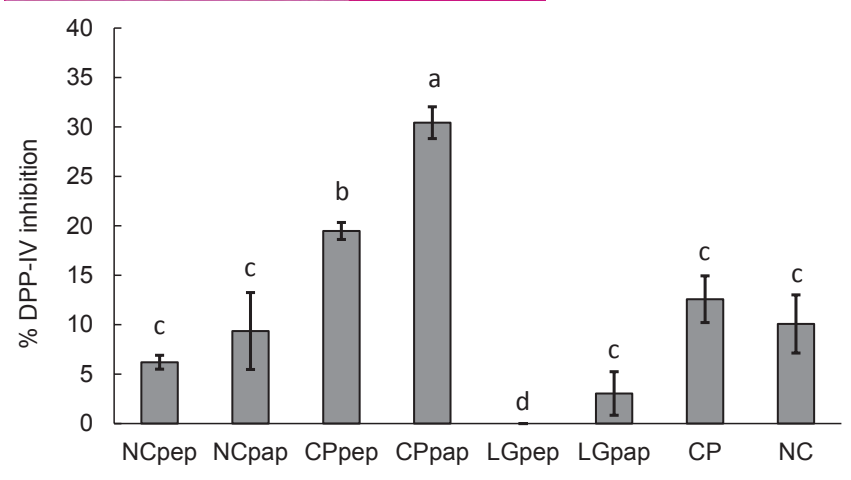

FIGURE 5 Dipeptidyl peptides (DPP)-IV inhibitory activity of the yellow mealworm cuticular (CP) and non-cuticular protein (NC), and bovine $\beta$-lactoglobulin before and after hydrolysis with pepsin or papain. Bar with different letters are significantly different $(p<.05)$ mean values. NCpep: non-cuticular protein hydrolyzed with pepsin, NCpap: non-cuticular protein hydrolyzed with papain, CPpep: cuticular protein hydrolyzed with pepsin, CPpap: cuticular protein hydrolyzed with papain, LGpep: $\beta$-lactoglobulin hydrolyzed with pepsin, and LGpap: $\beta$-lactoglobulin hydrolyzed with papain

TABLE 1 DPP-IV half-maximal inhibitory concentration of yellow mealworm cuticular protein hydrolyzed with papain, and hydrolysates from other protein sources reported in the literature

\begin{tabular}{|c|c|c|}
\hline Hydrolysate & $\mathrm{IC}_{50}(\mathrm{mg} / \mathrm{ml})$ & Reference \\
\hline $\begin{array}{l}\text { Cuticular protein hydro- } \\
\text { lyzed with papain }\end{array}$ & $0.825 \pm 0.020$ & This study \\
\hline Diprotin A & $0.008 \pm 0.002$ & This study \\
\hline Soy protein & 0.86 & $\begin{array}{l}\text { Nongonierma and } \\
\text { FitzGerald (2015) }\end{array}$ \\
\hline Pea protein & 0.96 & $\begin{array}{l}\text { Nongonierma and } \\
\text { FitzGerald (2015) }\end{array}$ \\
\hline Navy bean protein & 0.093 & $\begin{array}{l}\text { Mojica, Chen, and } \\
\text { de Mejía (2014) }\end{array}$ \\
\hline Chicken feet & $3.57 \pm 0.36$ & $\begin{array}{l}\text { Hatanaka, } \\
\text { Kawakami, and } \\
\text { Uraji (2014) }\end{array}$ \\
\hline Fish scale & $3.50 \pm 0.23$ & $\begin{array}{l}\text { Hatanaka et al. } \\
\text { (2014) }\end{array}$ \\
\hline Lesser mealworm protein & $0.54-0.66$ & Lacroix et al. (2019) \\
\hline $\begin{array}{l}\text { Tropical branded cricket } \\
\text { protein }\end{array}$ & $0.40-1.01$ & $\begin{array}{l}\text { Nongonierma et al. } \\
\text { (2018) }\end{array}$ \\
\hline
\end{tabular}

precursors of DPP-IV inhibitors. This approach facilitated the identification of a relationship between the protein biological roles, physicochemical properties, and frequency of bioactive peptide release by a given protease. Undigested NC and CP exhibited similarly weak DPP-IV inhibitory activity as NC hydrolysates (Figure 5). This was unexpected as the parent proteins would not bind the enzyme due to steric hindrance, and functional peptide motifs within the protein sequence become active only upon release by enzymatic or other hydrolysis methods. Yi et al. (2017) reported that proteins extracted from whole yellow mealworm contained $18-36 \mathrm{mg} / \mathrm{g}$ of phenolic 
compounds. It is possible that these compounds or salt present in the protein samples might be contributing to DPP-IV inhibition. Protein hydrolysis may have also occurred due to endogenous proteases present in Tenebrio molitor gut to release inhibiting peptides. There was no apparent DPP-IV inhibition by $\beta$-Lg hydrolyzed with pepsin. $\beta$ - Lg is mostly resistant to hydrolysis by pepsin (Brandelli, Daroit, \& Corrêa, 2015; Lacroix \& Li-Chan, 2013), potentially limiting the release of DPP-IV inhibiting peptides contained in its sequence. Previous studies have reported different (plant, fish, edible insect) protein hydrolysates with DPP-IV inhibitory activity; select IC ${ }_{50}$ values are presented in Table 1. With different protein compositions, proteases used for hydrolysis, and assay methods, it is difficult to compare the literature bioactivity data with the activity of CPpap in our study. Diprotin A, a tripeptide with potent DPP-IV inhibitory activity, was therefore used as positive control and found to have $I C_{50}$ value two orders of magnitude lower (i.e., higher activity) than that of the CP hydrolysates (Table 1).

\section{4 | CONCLUSION}

In this study, bioinformatics facilitated the structure-informed processing of cuticular proteins from edible yellow mealworm as promising precursors of DPP-IV inhibiting peptides. This study resulted in two major contributions: (1) compartmentalization of proteins in mealworm as an important factor in determining their potential as precursors of DPP-IV inhibiting peptides; this was due to the hydrophobic characteristics of amino acids of the cuticular proteins, linked to their biological functions as structural/protective barriers; and (2) bioinformatics as a promising tool for classifying protein precursors of bioactive peptides prior to in vitro processing and analysis. The findings are useful toward the application of mealworm larvae as sustainable protein sources for production of peptide-based functional ingredients and nutraceuticals for managing T2D. Further studies are however needed to demonstrate in vivo functions, including effects on endogenous DPP-IV levels and activity, incretins, insulin secretion, and blood glucose levels, as well as the absorption and bioavailability of the bioactive peptides produced from the mealworm cuticular proteins.

\section{CONFLICT OF INTEREST}

The authors have declared no conflicts of interest for this article.

\section{ORCID}

Isabelle M. E. Lacroix (iD https://orcid.org/0000-0003-4185-5753

Vincenzo Fogliano iD https://orcid.org/0000-0001-8786-9355

Chibuike C. Udenigwe iD https://orcid.org/0000-0001-8802-7707

\section{REFERENCES}

Acquah, C., Di Stefano, E., \& Udenigwe, C. C. (2018). Role of hydrophobicity in food peptide functionality and bioactivity. Journal of Food Bioactives, 4, 88-98. https://doi.org/10.31665/JFB.2018.4164
Agyei, D., Tsopmo, A., \& Udenigwe, C. C. (2018). Bioinformatics and peptidomics approaches to the discovery and analysis of food-derived bioactive peptides. Analytical and Bioanalytical Chemistry, 410(15), 3463-3472. https://doi.org/10.1007/s00216-018-0974-1

Andersen, S. O. (2002). Characteristic properties of proteins from pre-ecdysial cuticle of larvae and pupae of the mealworm Tenebrio molitor. Insect Biochemistry and Molecular Biology, 32(9), 1077-1087. https://doi.org/10.1016/s0965-1748(02)00045-0

Andersen, S. O., Hojrup, P., \& Roepstorff, P. (1995). Insect cuticular proteins. Insect Biochemistry and Molecular Biology, 25(2), 153-176. https ://doi.org/10.1016/0965-1748(94)00052-j

Andersen, S. O., Rafn, K., Krogh, T. N., Hojrup, P., \& Roepstorff, P. (1995). Comparison of larval and pupal cuticular proteins in Tenebrio molitor. Insect Biochemistry and Molecular Biology, 25(2), 177-187. https://doi. org/10.1016/0965-1748(94)00048-m

Azagoh, C., Ducept, F., Garcia, R., Rakotozafy, L., Cuvelier, M.-E., Keller, S., ... Mezdour, S. (2016). Extraction and physicochemical characterization of Tenebrio molitor proteins. Food Research International, 88, 24-31. https://doi.org/10.1016/j.foodres.2016.06.010

Bah, C. S. F., Bekhit, A.- E.-D.- A., Carne, A., \& McConnell, M. A. (2015). Production of bioactive peptide hydrolysates from deer, sheep and pig plasma using plant and fungal protease preparations. Food Chemistry, 176, 54-63. https://doi.org/10.1016/j.foodchem.2014.12.025

Barrett, A. J., Rawlings, N. D., \& Woessner, J. F. (1998). Handbook of proteolytic enzymes. London, UK: Academic Press.

Boachie, R. T., Okoro, F. L., Imai, K., Sun, L., Elom, S. O., Nwankwo, J. O., ... Udenigwe, C. C. (2019). Enzymatic release of dipeptidyl peptidase-4 inhibitors (gliptins) from pigeon pea (Cajanus cajan) nutrient reservoir proteins: In silico and in vitro assessments. Journal of Food Biochemistry, 43(12), e13071. https://doi.org/10.1111/jfbc.13071

Brandelli, A., Daroit, D. J., \& Corrêa, A. P. F. (2015). Whey as a source of peptides with remarkable biological activities. Food Research International, 73, 149-161. https://doi.org/10.1016/j.foodr es.2015.01.016

Cardamone, M., \& Puri, N. K. (1992). Spectrofluorimetric assessment of the surface hydrophobicity of proteins. Biochemical Journal, 282(2), 589-593. https://doi.org/10.1042/bj2820589

Cho, N. H. (2015). IDF diabetes atlas (7th ed.). Retrieved from https:// diabetesatlas.org/

de Souza Rocha, T., Hernandez, L. M. R., Chang, Y. K., \& de Mejía, E. G. (2014). Impact of germination and enzymatic hydrolysis of cowpea bean (Vigna unguiculata) on the generation of peptides capable of inhibiting dipeptidyl peptidase IV. Food Research International, 64, 799-809. https://doi.org/10.1016/j.foodres.2014.08.016

Edholm, T., Degerblad, M., Grybäck, P., Hilsted, L., Holst, J. J., Jacobsson, H., ... Hellström, P. M. (2010). Differential incretin effects of GIP and GLP-1 on gastric emptying, appetite, and insulin-glucose homeostasis. Neurogastroenterology and Motility, 22, 1191-1201. https://doi. org/10.1111/j.1365-2982.2010.01554.x

Hatanaka, T., Kawakami, K., \& Uraji, M. (2014). Inhibitory effect of collagen-derived tripeptides on dipeptidylpeptidase-IV activity. Journal of Enzyme Inhibition and Medicinal Chemistry, 29(6), 823-828. https:// doi.org/10.3109/14756366.2013.858143

Hsu, K.-C., Tung, Y.-S., Huang, S.-L., \& Jao, C.-L. (2013). Dipeptidyl peptidase-IV inhibitory activity of peptides in porcine skin gelatin hydrolysates. In B. Hernandez-Ledesma \& C. C. Hsieh (Eds.), Bioactive food peptides in health and disease (pp. 205-218). Rijeka, Croatia: IntechOpen. https://doi.org/10.5772/51264

Ishikawa, Y., Hira, T., Inoue, D., Harada, Y., Hashimoto, H., Fujii, M., ... Hara, H. (2015). Rice protein hydrolysates stimulate GLP-1 secretion, reduce GLP-1 degradation, and lower the glycemic response in rats. Food \& Function, 6(8), 2525-2534. https://doi.org/10.1039/c4fo0 $1054 \mathrm{j}$

Lacroix, I. M. E., Dávalos Terán, I., Fogliano, V., \& Wichers, H. J. (2019). Investigation into the potential of commercially available lesser 
mealworm (A. diaperinus) protein to serve as sources of peptides with DPP-IV inhibitory activity. International Journal of Food Science \& Technology, 54(3), 696-704. https://doi.org/10.1111/ijfs.13982

Lacroix, I. M. E., \& Li-Chan, E. C. Y. (2013). Inhibition of dipeptidyl peptidase (DPP)-IV and $\alpha$-glucosidase activities by pepsin-treated whey proteins. Journal of Agricultural and Food Chemistry, 61(31), 75007506. https://doi.org/10.1021/jf401000s

Lacroix, I. M. E., \& Li-Chan, E. C. Y. (2014). Isolation and characterization of peptides with dipeptidyl peptidase-IV inhibitory activity from pepsin-treated bovine whey proteins. Peptides, 54, 39-48. https:// doi.org/10.1016/j.peptides.2014.01.002

Lacroix, I. M. E., \& Li-Chan, E. C. Y. (2016). Food-derived dipeptidyl-peptidase IV inhibitors as a potential approach for glycemic regulation-Current knowledge and future research considerations. Trends in Food Science \& Technology, 54, 1-16. https://doi.org/10.1016/j. tifs.2016.05.008

Lafarga, T., Aluko, R. E., Rai, D. K., O'Connor, P., \& Hayes, M. (2016). Identification of bioactive peptides from a papain hydrolysate of bovine serum albumin and assessment of an antihypertensive effect in spontaneously hypertensive rats. Food Research International, 81, 91-99. https://doi.org/10.1016/j.foodres.2016.01.007

Minkiewicz, P., Dziuba, J., Iwaniak, A., Dziuba, M., \& Darewicz, M. (2008). BIOPEP database and other programs for processing bioactive peptide sequences. Journal of AOAC International, 91(4), 965-980.

Mochida, T., Hira, T., \& Hara, H. (2010). The corn protein, zein hydrolysate, administered into the ileum attenuates hyperglycemia via its dual action on glucagon-Like peptide-1 secretion and dipeptidyl peptidase-IV activity in rats. Endocrinology, 151(7), 3095-3104. https:// doi.org/10.1210/en.2009-1510

Moelbert, S. (2004). Correlation between sequence hydrophobicity and surface-exposure pattern of database proteins. Protein Science, 13(3), 752-762. https://doi.org/10.1110/ps.03431704

Mohan, A., \& Udenigwe, C. C. (2015). Towards the design of hypolipidaemic peptides: Deoxycholate binding affinity of hydrophobic peptide aggregates of casein plastein. Journal of Functional Foods, 18, 129136. https://doi.org/10.1016/j.jff.2015.06.064

Mojica, L., Chen, K., \& de Mejía, E. G. (2014). Impact of commercial precooking of common bean (Phaseolus vulgaris) on the generation of peptides, after pepsin-pancreatin hydrolysis, capable to inhibit dipeptidyl peptidase-IV. Journal of Food Science, 80(1), H188-H198. https://doi.org/10.1111/1750-3841.12726

Nielsen, P. M., Petersen, D., \& Dambmann, C. (2001). Improved method for determining food protein degree of hydrolysis. Journal of Food Science, 66(5), 642-646. https://doi.org/10.1111/j.1365-2621.2001. tb04614.x

Nongonierma, A. B., \& FitzGerald, R. J. (2013). Inhibition of dipeptidyl peptidase IV (DPP-IV) by proline containing casein-derived peptides. Journal of Functional Foods, 5(4), 1909-1917. https://doi. org/10.1016/j.jff.2013.09.012

Nongonierma, A. B., \& FitzGerald, R. J. (2014). An in silico model to predict the potential of dietary proteins as sources of dipeptidyl peptidase IV (DPP-IV) inhibitory peptides. Food Chemistry, 165, 489-498. https://doi.org/10.1016/j.foodchem.2014.05.090

Nongonierma, A. B., \& FitzGerald, R. J. (2015). Investigation of the potential of hemp, pea, rice and soy protein hydrolysates as a source of dipeptidyl peptidase IV (DPP-IV) inhibitory peptides. Food Digestion:
Research and Current Opinion, 6(1-3), 19-29. https://doi.org/10.1007/ s13228-015-0039-2

Nongonierma, A. B., Lamoureux, C., \& FitzGerald, R. J. (2018). Generation of dipeptidyl peptidase IV (DPP-IV) inhibitory peptides during the enzymatic hydrolysis of tropical banded cricket (Gryllodes sigillatus) proteins. Food \& Function, 9(1), 407-416. https://doi. org/10.1016/10.1039/C7FO01568B

Udenigwe, C. C. (2014). Bioinformatics approaches, prospects and challenges of food bioactive peptide research. Trends in Food Science \& Technology, 36(2), 137-143. https://doi.org/10.1016/j.tifs.2014.02.004

Udenigwe, C. C. (2016). Towards rice bran protein utilization: In silico insight on the role of oryzacystatins in biologically-active peptide production. Food Chemistry, 191, 135-138. https://doi.org/10.1016/ j.foodchem.2015.01.043

Udenigwe, C. C., \& Aluko, R. E. (2012). Food protein-derived bioactive peptides: Production, processing, and potential health benefits. Journal of Food Science, 77(1), R11-R24. https://doi. org/10.1111/j.1750-3841.2011.02455.x

Udenigwe, C. C., \& Fogliano, V. (2017). Food matrix interaction and bioavailability of bioactive peptides: Two faces of the same coin? Journal of Functional Foods, 35, 9-12. https://doi.org/10.1016/j.jff.2017.05.029

Xu, Q., Hong, H., Wu, J., \& Yan, X. (2019). Bioavailability of bioactive peptides derived from food proteins across the intestinal epithelial membrane: A review. Trends in Food Science \& Technology, 86, 399-411. https://doi.org/10.1016/J.TIFS.2019.02.050

Yi, L., Lakemond, C. M. M., Sagis, L. M. C., Eisner-Schadler, V., van Huis, A., \& van Boekel, M. A. J. S. (2013). Extraction and characterisation of protein fractions from five insect species. Food Chemistry, 141(4), 3341-3348. https://doi.org/10.1016/j.foodchem.2013.05.115

Yi, L., Van Boekel, M. A. J. S., Boeren, S., \& Lakemond, C. M. M. (2016). Protein identification and in vitro digestion of fractions from Tenebrio molitor. European Food Research and Technology, 242(8), 1285-1297. https://doi.org/10.1007/s00217-015-2632-6

Yi, L., Van Boekel, M. A. J. S., \& Lakemond, C. M. M. (2017). Extracting Tenebrio molitor protein while preventing browning: Effect of $\mathrm{pH}$ and $\mathrm{NaCl}$ on protein yield. Journal of Insects as Food and Feed, 3(1), 21-31. https://doi.org/10.3920/jiff2016.0015

Zhao, X., Vázquez-Gutiérrez, J. L., Johansson, D. P., Landberg, R., \& Langton, M. (2016). Yellow mealworm protein for food purposesExtraction and functional properties. PLoS ONE, 11(2), e0147791. https://doi.org/10.1371/journal.pone.0147791

\section{SUPPORTING INFORMATION}

Additional supporting information may be found online in the Supporting Information section.

How to cite this article: Dávalos Terán I, Imai K, Lacroix IME, Fogliano V, Udenigwe CC. Bioinformatics of edible yellow mealworm (Tenebrio molitor) proteome reveal the cuticular proteins as promising precursors of dipeptidyl peptidase-IV inhibitors. J Food Biochem. 2019;00:e13121. https://doi. org/10.1111/jfbc.13121 